\title{
RBEP
}

\section{0 trabalho docente do professor formador no contexto atual das reformas e das mudanças no mundo contemporâneo}

Marli Eliza Dalmazo Afonso de André

Patrícia C.Albieri de Almeida

Marcia de Souza Hobold

Neusa Banhara Ambrosetti

Laurizete Ferragut Passos

Ana Lúcia Manrique

\section{Resumo}

Discute dados de uma pesquisa que focaliza o trabalho do professor formador. Optou-se por debater os principais desafios apontados pelos professores, bem como as estratégias por eles utilizadas no enfrentamento das novas demandas do seu trabalho. Foram realizados quatro estudos de caso em universidades de diferentes regiões do País, públicas e privadas, entrevistados 53 professores formadores, e analisados projetos pedagógicos. Os resultados das análises revelaram muitas mudanças no alunado que busca os cursos de formação, o que leva os professores formadores a reconstruir seus saberes e suas práticas. Essas mudanças não são incorporadas pelos projetos institucionais, deixando à iniciativa individual dos formadores a tarefa de enfrentá-las.

Palavras-chave: trabalho docente; professor formador; contexto institucional; mudanças sociais. 


\section{Abstract \\ The docent work of teacher educators in the context of reforms and changes in contemporary world}

Based on data from a research that focus on the work of teachers' educators, we discuss the main challenges pointed out by teachers and their strategies to cope with new work demand. Four case studies were carried out in public and private universities from different Brazilian regions, 53 teacher educators were interviewed, and pedagogical projects were analyzed. The results show many changes in the students' characteristics, what called for a revision of educators' knowledge and practices. We find that these changes are not being considered in institutional projects, what leaves to teacher educators themselves the task of facing them.

Keywords: docent work; teacher educators; institutional context; social changes.

\section{Introdução}

No Brasil, as reformas educacionais implantadas nos últimos dez anos atribuem ao professor um papel central na melhoria do processo educativo. A formação do docente tornou-se, então, um dos temas mais importantes na agenda das reformas. Espera-se muito dos cursos de formação inicial e, consequentemente, dos professores formadores.

Em consonância com esse ideário das reformas, o Conselho Nacional de Educação (CNE), por meio da Resolução $n^{\circ} 1$, de 18 de fevereiro de 2002 (Brasil. CNE, 2002), resolve que toda formação de professores deverá observar alguns princípios norteadores, tais como: a existência de coerência entre a formação oferecida e a prática esperada do professor; a concepção nuclear será pela competência; e o foco no processo de ensino e de aprendizagem será a pesquisa.

Ainda segundo essa Resolução, os conhecimentos exigidos para a formação dos professores deverão contemplar: a cultura geral e profissional; os conhecimentos a respeito da criança, do adolescente, de jovens e adultos; os conhecimentos sobre dimensão cultural, social, política e econômica da educação; os conteúdos das áreas de conhecimento que serão objeto de ensino; os conhecimentos pedagógicos; e os conhecimentos advindos da experiência.

Inspiradas em concepções também vigentes em outros países, as novas proposições enfatizam a formação de nível superior como fonte de 
legitimação e valorização do trabalho docente. Há uma expectativa social quanto ao papel dos cursos superiores no preparo de professores competentes e qualificados, articulada à defesa desse modelo de professor como elemento fundamental no encaminhamento das questões da educação.

Importante destacar, nesse contexto de exigências e expectativas, o aumento vertiginoso do número de cursos de licenciatura e o consequente e significativo crescimento do número de alunos. Em 1991, segundo dados do Instituto Nacional de Estudos e Pesquisas Educacionais Anísio Teixeira (Inep), havia 2.512 cursos de licenciatura no País. Dados de uma pesquisa da Fundação Carlos Chagas (Gatti, Barreto, 2009) mostram que esses números chegam a 7.456, em 2006, com um contingente de 1.162.115 alunos, o que evidencia um crescimento vertiginoso das licenciaturas, desde a década de 90.

As exigências legais, somadas às circunstâncias atuais do crescimento dos cursos de licenciatura, não têm alterado o contexto de valorização dos professores que neles atuam, e, como apontou Cunha (2000, 2004), a lógica de estruturação desses cursos traz preocupações em relação à qualidade da formação que propiciam. A mesma autora, ao discutir as estratégias neoliberais presentes na legislação atual, denuncia que as condições de trabalho do docente e sua função social não são privilegiadas. Afirma, ainda, que a lógica natural do trabalho do professor ficou invertida, pois o afasta da sua condição de árbitro do processo educativo, em função de um papel conjuntural determinado para ele e que está fortemente voltado para o atendimento aos parâmetros avaliativos.

Entretanto, essa expansão em ritmo acelerado não foi acompanhada de medidas e de políticas que assegurassem a realização de um trabalho de qualidade por parte dos professores formadores que atuam nos cursos de licenciatura. Gatti (1991), já no início da década de 90, chamava a atenção para o importante papel desses cursos e para o reforço a ser dado na articulação adequada das disciplinas específicas e formativas com a realidade concreta das escolas, com as experiências e com o conhecimento de que dispõe o professor. Cabe indagar em que medida esses cuidados vêm sendo tomados nos dias atuais.

Há que se considerar ainda as múltiplas possibilidades de formação expressas nas diferentes modalidades de cursos hoje propostos para formar o professor e que têm implicado uma variedade de condições de formação. Além das universidades, centros universitários, faculdades e institutos isolados passam a se responsabilizar pela tarefa de formar os professores, seja na modalidade presencial ou a distância. Nesse sentido, cada vez mais se impõe a necessidade de estudos mais aprofundados sobre os processos formativos e os agentes desses processos.

Ainda se sabe muito pouco sobre aquele que conduz a formação inicial de professores, isto é, o professor formador. E quando se abordam as especificidades do trabalho do docente que atua nos cursos de licenciatura, inúmeras questões surgem: Quem são os professores formadores no Brasil hoje? Quais as especificidades do trabalho desse professor? Como 
e em quais condições desenvolvem esse trabalho? Que desafios vêm enfrentando os professores formadores em seu exercício profissional?

Conhecer mais de perto quem é esse docente e quais as condições de que dispõe para desenvolver seu trabalho parece-nos essencial, pois, como afirma Imbernón (2002, p. 63),

essa formação, que confere o conhecimento profissional básico, deve permitir trabalhar em uma educação do futuro, o que torna necessário repensar tanto os conteúdos da formação como a metodologia com que estes são transmitidos, já que o modelo aplicado (planejamento, estratégias, recursos, hábitos e atitudes) pelos formadores dos professores atua como uma espécie de "currículo oculto" da metodologia.

Assim, de acordo com o autor, é essencial que se investiguem as práticas docentes do professor formador, porque não só os conteúdos trabalhados, mas as formas de trabalhá-los e os valores a eles associados vão constituir uma espécie de modelo para o futuro docente.

Com a intenção de contribuir com alguns elementos para repensar os cursos de formação inicial, o presente texto discute dados de uma pesquisa que tem como foco o trabalho do professor formador que atua nos cursos de licenciatura. Não sendo possível, nos limites deste artigo, abordar a multiplicidade de elementos que emergiram na análise dos dados, optouse por focalizar aspectos que se mostraram especialmente significativos: os principais desafios enfrentados pelos professores formadores, bem como as formas por eles encontradas para fazer face às novas demandas do seu trabalho docente, decorrentes principalmente das mudanças no mundo contemporâneo.

\section{A categoria trabalho e a atividade docente do professor formador}

De que trabalho se fala neste caso específico? Que bases epistemológicas fundamentam a categoria trabalho nesta pesquisa? Entende-se a categoria trabalho como aquela que engendra uma permanente reconstituição da atividade humana, responsável pela modificação do indivíduo e do meio em que vive. Para Vasquez (2007, p. 222),

[...] a atividade humana é, portanto, atividade que se orienta conforme os fins, e estes só existem através do homem, como produtos de sua consciência. Toda ação verdadeiramente humana exige certa consciência de um fim, o qual se sujeita ao curso da própria atividade.

O processo de constituição humana, que reverbera diretamente no meio em que o indivíduo vive, só é possível ocorrer em virtude da consciência, propriedade majoritariamente humana, que diferencia o homem dos outros animais. Marx e Engels (2002, p. 22) afirmam que "[...] a consciência nunca pode ser outra coisa senão o ser consciente, o ser dos homens é o seu processo real de vida". 
Para Vasquez (2007, p. 229), "[...] o trabalho humano é transformação de uma matéria à qual se imprime uma determinada forma, exigida não mais por uma necessidade prático-utilitária, mas por uma necessidade geral humana de expressão e comunicação". Ainda para o autor, "o homem se afirma, criando ou humanizando o que toca". Significa que como um escultor o homem tende a dar forma para aquilo com que/quem interage, seja concretamente, por meio da utilização de materiais, seja no plano das ideias (mundo abstrato).

O homem racional planeja e materializa suas ações, bem como realiza suas atividades de labor e consegue registrar essas experiências que são aperfeiçoadas e repassadas de geração em geração. É por meio do trabalho que o homem se constitui histórica e culturalmente e modifica o meio em que vive. O trabalho sempre esteve presente no bojo das relações sociais como necessário à sobrevivência.

Em consonância com o conceito de trabalho em geral, o trabalho docente é entendido como a práxis que constitui a atividade profissional. O professor, ao mesmo tempo que desenvolve a sua atividade profissional, contribui para que mudanças ocorram ao seu redor e, simultaneamente, reconstrói-se pelas experiências. Nesse processo, ele não só constitui a sua identidade, mas também colabora com ações, valores e práticas para a constituição identitária dos estudantes que o circundam.

Como bem explica Nóvoa (2000, p. 16):

A identidade não é um dado adquirido, não é uma propriedade, não é um produto. A identidade é um lugar de lutas e de conflitos, é um espaço de construção de maneiras de ser e estar na profissão. Por isso, é mais adequado falar em processo identitário, realçando a mescla dinâmica que caracteriza a maneira como cada um se sente e se diz professor. (grifo do autor).

Compreendendo a identidade na perspectiva de Nóvoa, reafirma-se a relevância dos cursos de formação inicial, pois têm um papel fundamental no processo de (re)constituição da identidade profissional dos futuros professores. É nesse período de formação que muitos estudantes (re)constroem modelos, imagens, maneiras de ser, pensar e agir na profissão.

A formação inicial pode contribuir para que o futuro professor construa uma "[...] bagagem sólida nos âmbitos científico, cultural, contextual, psicopedagógico e pessoal que deve capacitá-lo a assumir a tarefa educativa em toda sua complexidade, atuando reflexivamente com a flexibilidade e o rigor necessários" (Imbernón, 2002, p. 60).

Investigar o trabalho docente do formador também significa questionar o ato de ensinar. Para Tardif (2005, p. 31), "ensinar é trabalhar com seres humanos, sobre seres humanos, para seres humanos. Esta impregnação do trabalho pelo 'objeto humano' merece ser problematizada por estar no centro do trabalho docente".

Tendo essa concepção da categoria trabalho, direcionamos nossos olhares para a atividade que desenvolve o professor formador. Entende-se como formadores, conforme Mizukami (2005, p. 69-70), aqueles 
[...] envolvidos nos processos formativos de aprendizagem da docência de futuros professores ou daqueles que já estão desenvolvendo atividades docentes: os professores das disciplinas práticas de ensino e estágio supervisionado, os das disciplinas pedagógicas em geral, os das disciplinas específicas de diferentes áreas do conhecimento e os profissionais que acolhem os futuros professores.

\section{Procedimentos metodológicos}

Optou-se pela abordagem qualitativa de pesquisa que, segundo André (2005, p. 47), tem como centro de preocupação "[...] o mundo dos sujeitos, os significados que atribuem às suas experiências cotidianas, sua linguagem, suas produções culturais e suas formas de interações sociais".

Nessa perspectiva, decidiu-se pelo delineamento de quatro estudos de caso, que nos permitem conhecer uma instância em particular, levando em conta seu contexto e sua complexidade. O contexto, nesta pesquisa, refere-se à cultura institucional, ou seja, as ações, as linguagens e outras formas de comunicação de um grupo de sujeitos que estão envolvidos no processo de formação, assim como as normas que os regem e as formas de organização do seu trabalho.

Seguindo indicações de Nisbet e Watt (1978), a primeira fase dos estudos de caso é exploratória, momento de definir a(s) unidade(s) de análise - os casos -, confirmar - ou não - as questões iniciais, estabelecer os contatos iniciais para entrada em campo, localizar os participantes e estabelecer mais precisamente os procedimentos e instrumentos de coleta de dados. Na presente pesquisa, um dos critérios para escolha das unidades de análise foi o tipo de dependência administrativa da instituição, além, evidentemente, de oferecer cursos de licenciatura e de possibilitar o acesso aos dados. Assim, foram escolhidas uma instituição pública, uma privada e duas mistas, ou autárquicas, localizadas nas Regiões Sudeste e Sul do País.

As duas instituições denominadas mistas (A e B) são universidades tradicionais e conceituadas na região em que estão inseridas. Uma localiza-se no interior da Região Sudeste e a outra, no interior da Região Sul. São universidades de grande porte que oferecem cursos de graduação e de pós-graduação em diferentes áreas do conhecimento. Apesar de essas instituições terem uma organização institucional semelhante à de uma universidade pública, os recursos financeiros são provenientes basicamente da mensalidade dos alunos. Nas duas instituições, há professores de carreira, porém as formas de ingresso e as condições de trabalho têm características próprias. Em uma das universidades, os professores participam amplamente nas decisões dos vários conselhos institucionais.

Na instituição pública (C), foi escolhida uma unidade que atende a quase 5 mil alunos de licenciatura de diferentes institutos, assim como cerca de 890 alunos do curso de Pedagogia. Dos três departamentos 
da unidade, foi selecionado aquele que conta com docentes de áreas específicas, mas são responsáveis pelas metodologias de ensino. Todos os docentes são doutores, ingressaram pela via do concurso público e têm as prerrogativas do funcionalismo público.

A instituição privada (D) é uma faculdade isolada e está localizada num bairro industrial de uma cidade do interior da Região Sudeste do País. Oferece nove cursos de graduação, dos quais cinco são exclusivamente de licenciatura, e também curso de especialização em Educação Matemática. Os dados coletados nesta instituição referem-se apenas aos professores do curso de Matemática.

Estabelecidos os contatos iniciais, deu-se prioridade ao uso de entrevistas e à análise documental. Como nos ensina Stake (1995), a entrevista é a melhor forma de investigar os significados atribuídos pelos sujeitos a uma dada situação. Os entrevistados foram 53 professores $^{1}$ das disciplinas específicas ou pedagógicas. Procurou-se entrevistar pelo menos 30\% dos docentes que atuavam na licenciatura de cada instituição, contemplando, quando possível, docentes com formação em diferentes áreas de conhecimento.

Para a realização das entrevistas, foi elaborado um roteiro baseado nas questões e nos objetivos da pesquisa, o qual foi utilizado em entrevistas-piloto com formadores que não faziam parte do grupo de sujeitos; essa testagem foi fundamental para aprimorar o instrumento de pesquisa. As entrevistas, marcadas com antecedência, tiveram a duração aproximada de uma hora e meia e foram gravadas com autorização dos depoentes. Após a transcrição, algumas foram devolvidas aos formadores para confirmação ou correção dos dados.

Para investigar a relação entre os contextos institucionais e a atuação dos formadores, foram analisados os projetos político-pedagógicos das instituições e realizadas entrevistas com docentes diretamente envolvidos na elaboração ou implementação desses projetos.

É possível, como afirma Stake (1995, p. 68), que o documento possa substituir o registro de um evento que o pesquisador não pôde observar diretamente. Documentos são muito úteis nos estudos de caso, porque complementam informações obtidas por outras fontes e fornecem base para triangulação dos dados.

\section{Contexto de mudanças e novas demandas ao trabalho do formador}

Dois conjuntos de dados serão aqui discutidos: um deles refere-se às mudanças apontadas pelos professores formadores, as quais estão muito relacionadas com as transformações no perfil do aluno que vem ingressando nas licenciaturas, o que interfere no seu trabalho e na sua profissionalidade; o outro diz respeito às tentativas de respostas dos formadores às novas demandas que, ao mesmo tempo que mobilizam ações comprometidas e um empenho pessoal desses professores, revelam a ausência de uma política institucional para o enfrentamento desses desafios.

Os depoimentos dos formadores revelam como as transformações econômicas, sociais e culturais em curso na sociedade contemporânea vêm

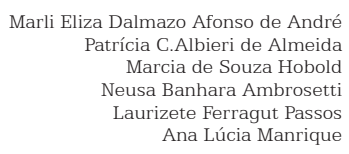
Ana Lúcia Manrique 
afetando o trabalho dos docentes, os alunos que eles buscam formar, suas estratégias e as práticas de ensino. Entre essas mudanças, destacam-se aquelas relativas ao perfil do estudante que ingressa na universidade, trazendo novas demandas ao trabalho dos formadores, que buscam reconstruir seus saberes e adequar suas práticas em resposta a esses desafios. Observa-se que as instituições universitárias têm dificuldade de lidar com essas novas necessidades de professores e alunos, especialmente pela permanência de formas de organização e de uma cultura institucional que favorecem a fragmentação e o isolamento do trabalho docente.

\section{O desafio de formar o novo aluno da licenciatura}

A mudança no perfil do aluno que ingressa na universidade foi muito enfatizada nas entrevistas, especialmente pelos professores das instituições privadas. Se o perfil do aluno do curso de licenciatura mudou, pergunta-se: Que mudanças seriam essas? Como essas mudanças são percebidas pelos professores?

Os aspectos mais recorrentes nos depoimentos dizem respeito às mudanças de interesse, motivação, postura e expectativas desse novo aluno, em especial a relação que ele estabelece com a docência e a situação de precariedade da escola básica.

O que se mostra nos depoimentos dos formadores são alunos que têm com o conhecimento uma relação utilitarista e ingressam na universidade sem o domínio dos conhecimentos básicos, que deveriam ter sido adquiridos na escolarização anterior. Note-se, em alguns pequenos trechos, como os professores se referem ao aluno:

[...] eu sinto que os alunos de graduação que chegam pra gente chegam cada vez menos preparados para uma graduação. (Francisco, Educação Física, Instituição B).

[...] eles chegam aqui já com defasagem, não é possível que se dê, ou melhor, que se recupere em pouco tempo tudo aquilo que eles perderam. (Nena, Letras, Instituição A).

Os formadores chamam a atenção para vários aspectos das mudanças observadas nos estudantes e identificam um fenômeno que parece presente em todos os níveis de ensino: alunos mais pragmáticos e utilitaristas. O depoimento da professora Bruna ilustra essa questão:

[...] a gente tem encontrado alunos muito diferentes, com expectativas muito diferentes, geralmente muito apressados. Eles vêm buscar uma formação muito rápida, então, tem sido um pouco difícil convencê-los da fundamentação para essas práticas. (Bruna, Pedagogia, Instituição B).

Esse relato é ilustrativo do que Tardif e Lessard (2005, p. 147) chamam de "pragmatização dos conhecimentos, da formação e da cultura", que mantém forte relação com a constituição de uma "[...] sociedade totalmente orientada para o funcional e o útil". Para os autores, a hipótese 
é que os saberes transmitidos pela escola se orientam por uma lógica de mercado e explicam que o estado atual do ensino tem causas históricas e datadas, relacionadas à massificação e à generalização do ensino destinado à preparação de uma mão de obra qualificada para atender ao desenvolvimento econômico.

$\mathrm{O}$ atual contexto de mudança age como elemento transformador do trabalho docente, à medida que tem modificado a relação entre professores e alunos e tornado inconciliável o modelo tradicionalmente valorizado de escola e de ensino com o atual contexto de transformações, o que significa que o ideal de uma escola como ambiente de cultura se altera. Esse quadro resulta em problemas: "[...] diversas formas de desrespeito pela função docente ou pelo adulto que a cumpre, ou ainda uma incapacidade de funcionar segundo regras usuais de civilidade da instituição, recusa de empenhar-se no trabalho escolar, indisciplina, violência gratuita, etc" (Lessard, Tardif, 2008, p. 258).

Essas transformações de que falam os autores também têm seus efeitos no ensino superior, lembrando que a maioria dos alunos ingressa muito jovem na universidade. Os professores relatam situações cotidianas que os incomodam e dificultam a relação com os discentes, como o desrespeito às regras, o comportamento displicente durante as aulas, a insuficiente valorização do conhecimento teórico e sistematizado, o imediatismo, entre outros.

Os entrevistados mostram-se angustiados com o comportamento do aluno em relação a si próprio e ao curso. O que parece pesar para a maioria dos formadores diz respeito aos significados que os licenciandos atribuem ao ser professor e à formação para a docência. Os formadores manifestam a preocupação em despertar no estudante o interesse pela formação profissional, em ajudá-lo não só a perceber-se professor, como também a conscientizar-se de que a docência requer posturas éticas e profissionais, o que passa pela relação do licenciando com a disciplina que será objeto de ensino. Os depoimentos do professor Antônio e do professor Raí também trazem elementos para essa discussão:

[...] alguns ainda estão em dúvida de fazer estágio curricular obrigatório, que eles têm que desempenhar nas escolas. Muitos não querem isso para a vida profissional. Dizem: Não. Vou trabalhar com meio ambiente, com ecologia e não quero ser professor. (Antônio, Ciências Biológicas, Instituição A).

[...] o grande obstáculo que eu sinto é que eles entram na licenciatura e muitos não pretendem dar aula, mas estão fazendo o curso de licenciatura em Matemática, que vai torná-los professores de Matemática e não outro, senão professor de Matemática. No final, eles acreditam que sabem Matemática ou que saberão muita Matemática e as outras coisas não são importantes. (Raí, Matemática, Instituição D).

Perceber no aluno, futuro professor, a falta de motivação para a docência e de um movimento de autoimplicação no seu próprio processo formativo constitui um desafio e consome muito tempo e energia do 
docente, transformando, inclusive, as relações com o próprio trabalho e gerando sentimentos que afetam sua autoestima. Note-se o que diz a professora Maitê:

[...] eu não aguento esse povo que está aqui sem vocação; eu acho que isso foi muito o que me frustrou, eu não consegui passar o que eu acho que é o meu melhor e eu acho que eu não consegui atingi-los, ajudá-los a terem confiança no melhor deles. Para dar aula ficou um negócio, assim, de passar matéria. (Maitê, Letras, Instituição B).

Esse trecho do depoimento da professora traz um desabafo sobre o que se encontra na sala de aula, a dificuldade de atingir os alunos e as consequências de sua frustração. O relato dela continua:

Eu tive um problema, no passado, de esgotamento; eu só fui agora me aperceber do que foi isso, foi dessa frustração de eu achar que eu não estou formando tão bem professores como eu acho que eu deveria formar, por uma questão até de honrar os professores que eu já tive antes. Foi um desgaste que eu tive tremendo no passado e agora que eu estou achando que eu estou melhorando [...]. (Maitê, Letras, Instituição B).

A professora descreve claramente como a reação dos alunos afetou sua profissionalidade, seus conhecimentos profissionais, seus valores e suas atitudes. Outros professores, como Ramona e Raí, juntam-se ao desabafo:

[...] eu percebo que, no final do curso, menos da metade da classe eu considero que eu formei um bom professor e que uma grande parte dos alunos eu sugiro formação continuada, busca de outras instâncias de formação [...] Então, isso eu senti muito esse ano, foi o mais frustrante da carreira, foi essa turma, em termos de aula, de formação, foi mais frustrante até o presente. (Ramona, Pedagogia, Instituição B).

[...] eu fiquei surpreso, porque eu achava que a coisa ia mais a fundo, eu acreditava que conseguiria me aprofundar mais no conteúdo [...] Talvez pelo curso, pelo tempo curto que nós temos, três anos para formar um professor de Matemática para professores ou para estudantes que chegam sem dominar o conteúdo básico, eu acho que é impossível. (Raí, Instituição D).

Esse sentimento de frustração em relação ao pouco aproveitamento dos alunos é uma realidade, principalmente nas instituições privadas. No caso da instituição pública, os formadores se dizem satisfeitos com a bagagem cultural e com o aproveitamento dos estudantes; no entanto, manifestam uma preocupação que é muito séria: convencer os alunos a não desistirem da docência. Vejamos o que diz o professor Carlos:

[...] o desafio mesmo é o de discutir com os alunos a própria perspectiva do que é ser professor, de que esses alunos se convençam de que ser professor é importante. (Carlos, Física, Instituição C).

Essa é uma questão que se torna ainda mais séria no caso dos alunos das disciplinas de Física, Química, Biologia e Matemática, pois nos 
institutos de origem a licenciatura é pouco prestigiada e a formação do aluno se volta basicamente para torná-lo um pesquisador. Esse fato, que faz parte da cultura institucional, agrava ainda mais a tarefa do professor formador:

Acho que tem uma questão que é muito presente e isso também não é de hoje. Que a nossa função no curso é, talvez, conquistar o aluno ou convencer o aluno de que ser professor é algo interessante. Eu tenho isso como preocupação. Apesar dos dissabores, das grandes dificuldades, etc [...] Às vezes o aluno vem muito diminuído, também, dos cursos de licenciatura. Vem com uma autoestima baixa. (Mário, Matemática, Instituição C).

A tarefa de motivar os alunos para o exercício da docência exige que o professor mobilize diferentes saberes, recorra a diferentes estratégias didáticas, reveja suas crenças e princípios e repense seu papel de formador.

Um outro elemento que interfere significativamente na prática docente do formador diz respeito às dificuldades de leitura e de escrita dos alunos e à ausência, em muitos casos, de domínio dos conhecimentos escolares e das habilidades básicas para poder ensinar. Esse é um fato que fica mais evidente nas instituições privadas, mas também foi citado por uma professora de instituição pública:

[...] o aluno que chega no ensino superior sem gostar de ler, então ele acha que pode fazer a faculdade, fazer a licenciatura só anotando algumas coisas que são passadas na lousa sem buscar absolutamente nada; e se não lê, consequentemente, não consegue escrever, tem muita dificuldade de escrita. (Cláudia, Pedagogia, Instituição B).

[...] dificuldade de leitura, a dificuldade de escrita dos nossos alunos. Nós temos excelentes alunos, têm alunos bons, alunos que escrevem, que perguntam. Mas tem uma quantidade de alunos que a gente percebe que foi passando, passando, que infelizmente mal escreve, que tem uma interpretação muito ruim e tem uma dificuldade imensa. (Débora, Letras, Instituição A).

O que eu sinto é uma queda na cultura geral deles, na escrita deles. É uma baixa de qualidade geral muito grande. De vez em quando, eu peço um fichamento, um resumo, justamente para ir verificando como é a escrita deles, o que eles entendem, como é que eles foram formados, em vez de pedir só o relatório no final. Às vezes causa um impacto, uma pobreza, é uma pena. Tem gente que tem uma participação tão boa em sala de aula e quando você vai ver a escrita [...]. (Paula, Letras, Instituição C).

Enfrentamos alunos com rombo de conhecimento enorme, com total dificuldade de leitura, às vezes eles param para perguntar o significado de uma determinada palavra que a gente falou, não que falemos difícil, procuramos ter a linguagem mais simples possível, e mesmo assim algumas coisas eles não entendem, então é essa nossa clientela. (Sueli, Instituição D).

Os depoimentos revelam a angústia dos professores face à falta de repertório dos alunos, às dificuldades de escrita e à falta de leitura. 
São manifestações do processo precário de escolarização dos estudantes e denunciam a situação trágica da escola básica brasileira, principalmente a pública.

Uma pesquisa realizada por Marin e Giovanni $(2006,2007)$ mostra que alunas concluintes de cursos de formação de professores têm domínio muito precário dos conteúdos escolares básicos relacionados à leitura e à escrita. Fundamentadas em Bourdieu, as autoras concluem que o capital cultural veiculado pela ação da escola não permitiu às professoras superarem totalmente o capital cultural familiar, o que significa que "[...] as esferas escolares que compuseram a trajetória escolar desses alunos não foram incisivas para a aquisição de disposições duráveis no uso da língua, na leitura e na expressão escrita com correção" (Bourdieu apud Marin, Giovanni 2007, p. 37). Ao que parece, isso tem ocorrido com um número significativo de estudantes das licenciaturas. Os formadores identificam a falta de domínio dos bens culturais e simbólicos que a língua escrita representa, bem como dos conteúdos que serão objeto de ensino:

Um desafio que eu enfrento é a questão do conteúdo, do domínio do conteúdo. Como eles chegam aqui já com defasagem, não é possível que se dê, ou melhor, que se recupere em pouco tempo tudo aquilo que eles perderam. Então isso me preocupa muito, porque eu penso e eu falo para eles, se você vai trabalhar com os alunos isto, você tem que saber isto. (Nena, Letras, Instituição A).

Trata-se de uma situação preocupante, especialmente quando se reconhece que o conhecimento do conteúdo, objeto de ensino, é um saber que está na base da profissão docente e que é fundamental o professor compreender as estruturas e os princípios da organização conceitual da disciplina que ensina. Espera-se que conheça a literatura acumulada e os estudos na área, bem como o conhecimento filosófico e histórico sobre a natureza desse conhecimento (Shulman, 2004).

Assim, quando se tem a compreensão de que o trabalho docente requer um conjunto de saberes e de que reconhecer um repertório de conhecimentos próprios ao ensino incide sobre a especificidade desse trabalho, do saber específico indispensável ao desenvolvimento dessa atividade docente (Roldão, 2005), pergunta-se: Como tratar, nos cursos de licenciatura, da precariedade da formação básica? Como formar um professor que não dispõe de conhecimentos escolares e habilidades básicas? As propostas de formação não teriam que assumir essa realidade?

Se, por um lado, os professores formadores enfrentam o desafio de lidar com estudantes que são marcados por uma história escolar deficitária, por outro, os futuros professores se defrontam, em suas atividades de estágio, com uma escola básica precária, o que os deixa inseguros sobre a opção profissional pela docência. O depoimento da professora Mara expressa muito claramente essa situação:

É uma coisa contraditória, porque você pede pra ele ver escola e quanto mais ele vê a escola, menos ele quer. Então, eles assumem um compromisso com a docência, muito interessante, mas não com a 
escola pública. Eles vão dar aula em ONGs; eles vão nesses cursinhos comunitários. Eles vão, eles querem dar aula, mas eles não querem dar aula em escola pública. E os que vão... alguns alunos... eu tenho seguido algumas coisas... eles ficam... é muito transitório, é pouco tempo que eles ficam na escola. (Mara, Geografia, Instituição C).

Convencer os alunos que é bom ser professor. Despi-los do medo e do preconceito. Porque, num certo sentido, eles têm razão. Sabe, eles não... Eles vão muito em escola onde os professores não têm o menor compromisso, nem sabem que devem ter algum compromisso com a sua profissão. Que qualquer profissão tem que ter. (Helena, História, Instituição C).

A realidade da escola básica brasileira, em especial da escola pública, assusta os estudantes e leva muitos deles a pensar em desistir, em mudar de profissão, como diz a professora Cristina:

E eu pergunto pros outros professores e, aí, alguns deles dizem que muitos alunos falam que estão muito desanimados, muitos por causa dessa ideia do estágio, que o estágio assusta muito, quer dizer, a realidade da escola assusta muito. Então muitos deles falam: ai não professora, eu não to preparado, eu não to preparado pra enfrentar essa situação de jeito nenhum, eu vou amadurecer mais, eu vou fazer outras coisas. (Cristina, História, Instituição C).

Fica, então, para o professor formador, a tarefa de fazer com que o futuro professor, junto com ele, analise criticamente a situação observada nas escolas, pondere todas as variáveis que concorrem para que o quadro seja assim tão precário e consiga separar a parte que compete ao docente e a que é de responsabilidade de outras instâncias. Com base nessa análise, para a qual o formador tem que recorrer a fundamentos socioantropológicos, psicossociais, sociopolíticos e socioeconômicos, talvez ele consiga convencer o estudante a permanecer no magistério. Mas essa não deveria ser uma tarefa individual: deveria fazer parte do projeto político-pedagógico e ser assumida pelo coletivo institucional.

Os dados desta pesquisa e os do estudo de Marin e Giovanni (2006, 2007) revelam que a situação de precariedade da educação básica brasileira gera novas exigências ao trabalho do professor formador. Como atuar frente a essa realidade? Esse questionamento nos dirige para o exame dos projetos político-pedagógicos dos cursos de formação.

Nos documentos institucionais analisados, essa questão é silenciada. Encontra-se apenas o perfil do professor que o curso pretende formar. Não há uma caracterização do aluno que ingressa no curso nem está previsto um acompanhamento dos egressos. É fundamental que os projetos de formação tenham como ponto de partida a compreensão da realidade em que atuam, o que implica levantar dados e informações sobre os alunos que ingressam nos cursos de licenciatura e suas necessidades. É imperativo analisar a realidade para identificar a que distância se está do perfil de profissional desejado, a fim de encontrar os caminhos possíveis de superação.

As dificuldades de leitura e produção de textos dos alunos, bem como a falta de domínio dos conteúdos escolares básicos, tão enfatizadas 
pelos professores, ao que parece, ainda não se tornaram uma preocupação institucional. Nos depoimentos, fica evidenciado como é difícil para o professor formador desempenhar o seu mandato: o aprendizado da docência. Os professores alegam que tem sido impraticável realizar esse mandato sem reorganizar o ensino e adequar o trabalho pedagógico ao perfil do aluno e às suas necessidades. No entanto, essas iniciativas se limitam ao âmbito individual.

\section{Dos desafios à busca de respostas para as novas demandas}

Como os professores formadores vêm enfrentando esses desafios? Como vêm atuando em resposta às novas demandas?

Os depoimentos revelam uma riqueza de detalhes sobre como alguns professores formadores experimentam sua condição e seu trabalho docente. Relatam situações que despertaram sentimentos de insatisfação e satisfação e analisam como essas experiências transformaram o próprio trabalho e mobilizaram ações em resposta às dificuldades enfrentadas.

As dificuldades dos licenciandos, especialmente em relação à leitura e à produção de textos, demandam reflexões e novas práticas e, muitas vezes, traduzem-se em dilemas:

[...] eu dava textos para eles lerem e eles não conseguiam entender, eu ficava desesperada, eu achava que tinha perdido a mão, não sabia mais dar aula. Eu sempre conseguia fazer o salto de onde o aluno estava para uma leitura de texto acadêmico, eu tinha sucesso, e ali eu tive que ficar o semestre inteiro trabalhando leitura com eles, e eles ainda não sabiam. Então, eu pedi autorização para a chefia para não seguir a apostila, resolvi ficar com essa turma até o final do ano fazendo só leitura [...]. (Maitê, Letras, Instituição B).

Ele vem com uma formação de leitura muito deficitária. E o curso tenta construir, mas o que nós percebemos é que, quando está finalizando o curso, ele está pronto para começar a se desenvolver como leitor autônomo. O curso dá um início de prontidão para que ele tenha autonomia de leitura, e daí quando ele entra no mercado de trabalho, o mercado vai exigir dele uma ação pragmática. (Guida, Letras, Instituição A).

Esses depoimentos ilustram que o pouco domínio dos sistemas simbólicos da língua por parte dos alunos, ferramentas essenciais para o desenvolvimento acadêmico e profissional, são fontes de questionamentos e de conflitos. A professora Maitê, por exemplo, precisou rever os objetivos do seu trabalho e tomar decisões que, nesse caso, consistiram em recuperar as dificuldades de leitura, em detrimento dos conteúdos estabelecidos no programa da disciplina.

Para alguns professores, as dificuldades de leitura e escrita dos alunos representam duplo desafio - favorecer o domínio da língua e a aprendizagem da docência - que exige, sem dúvida, um maior investimento emocional e pedagógico dos formadores. Emocional porque se trata de um trabalho "consumidor" de uma boa dose de energia afetiva, que é 
decorrente da natureza interpessoal das relações professor/alunos, e, consequentemente, pedagógico porque as atuais demandas do perfil e das necessidades dos estudantes colocam em xeque a profissionalidade docente e pressionam o professor a rever os objetivos formativos e as práticas desenvolvidas.

Entretanto, muitos professores formadores, como os da Educação Matemática, têm buscado oferecer condições para que seus alunos dominem os conhecimentos básicos necessários para sua atuação futura como docente:

São alunos, a maioria, que vêm da periferia, 99,9\% são da rede pública com uma defasagem de conhecimento, mas procuramos ter com eles uma relação humana e tentar motivá-los a aprender geometria e criar oficinas; temos laboratórios para que eles construam o conhecimento deles, são várias atividades sequenciais e eu tive bons resultados. [...] A partir do $2^{\circ}$ ano, eles são obrigados a comprar um computador, porque eles sabem que agora eles estão antenados, afilados, usando ferramentas e ferramenta tecnológica, é muito legal isso. (Danilo, Instituição D).

Nos depoimentos, há vários exemplos de como as necessidades dos alunos mobilizam o formador a buscar novas estratégias, para que seja possível obter os resultados desejados. Em alguns desses relatos, evidencia-se o conhecimento pedagógico dos professores, como organizam o conteúdo com a intenção de sistematizá-lo e torná-lo acessível ao aluno. Alguns professores expõem, com certa riqueza de detalhes, como pensam pedagogicamente o conteúdo, compreendem a disciplina e, inclusive, organizam o conhecimento de modo que possa ser compreendido pelo estudante (Shulman, 2004).

Um depoimento que chama a atenção é o da professora Alzira, que destaca uma grande preocupação em desenvolver nos alunos o que ela denomina de competência leitora e competência de produção de texto. Quando solicitada a descrever a sua prática docente, ela relata como aprendeu a trabalhar para auxiliar os estudantes a superarem as dificuldades de leitura e de escrita:

[...] tive que descobrir na sala de aula que a teoria da análise de discurso não me ajudava a ensinar o aluno a melhorar a competência em leitura e aí eu fui buscar, eu falei: tem que ter uma maneira, alguma teoria que possa me ajudar no efetivo trabalho dentro da sala de aula. Aí eu fui buscar as leituras da Ângela Kleiman; então, eu fui estudar a leitura interacionista, toda essa parte, o prisma interacionista em leitura e descobri algumas técnicas que me ajudavam na sala de aula. E funcionou sabe, é gradativo, mas tem um retorno, eu sinto por meio dos exercícios, [...] do contato com aluno, das conversas também em sala de aula e, sobretudo, esse retorno mesmo de exercício. (Alzira, Letras, Instituição B).

Esse depoimento ilustra como o professor pode operar com convicções, princípios e evidências que guiam suas ações e nos quais ele apoia suas escolhas (Shulman, 2004). Nesse caso, recorrer a uma fundamentação teórica foi essencial para buscar novas formas de organizar seu ensino e 
de fornecer retorno aos alunos. Ficou evidente o empenho da professora em desenvolver estratégias que favorecessem o aprendizado do discente, tanto é que dedica um bom tempo da entrevista para explanar como desenvolve a competência leitora e a de produção de texto dos alunos.

Os depoimentos mostram que as respostas dos professores aos desafios da prática docente podem favorecer a mobilização de ações comprometidas com as necessidades de formação dos alunos; mas evidenciam também o quanto esse esforço vem representando uma sobrecarga de trabalho que, somada às múltiplas tarefas do professor de ensino superior, vai invadindo os horários de descanso e a vida pessoal dos formadores:

O que eu sentia era isso: na hora da análise da situação, eles coletavam dados, mas para analisar aquilo eu precisava dar muito mais do que eu conseguia, eu atendia fora da sala de aula, eu vinha mais cedo, marcava para cada grupo antes da aula. (Roberta, Física, Instituição C).

[...] Então esse trabalho da prática, do estágio, eu acho maravilhoso, só que para eu fazer isso, eu tenho que ocupar as minhas noites, os meus fins de semana. (Paula, Letras, Instituição C).

Percebe-se, assim, o esforço individual dos professores para se adequarem às condições reais de trabalho, se pretendem oferecer algo mais aos seus alunos, podendo caracterizar um processo de intensificação do trabalho. Aspectos pessoais e subjetivos são diretamente atingidos pela intensificação, com forte incidência sobre o trabalho mental, conforme destaca Apple (1995, p. 39) ao chamar a atenção para as implicações dessa intensificação:

[...] Ela tem vários sintomas, do trivial ao mais complexo - desde não ter tempo sequer de ir ao banheiro, tomar uma xícara de café, até ter uma falta total de tempo para conservar-se em dia com sua área. Podemos ver a intensificação atuando mais visivelmente no trabalho mental, no sentimento crônico de excesso de trabalho, o qual tem aumentado ao longo do tempo.

\section{A tarefa de formar profissionalmente o aluno}

Um outro desafio com que os professores se defrontam diz respeito à tarefa de formar profissionalmente o aluno, promovendo condições para o aprendizado da docência e para a apropriação do saber profissional que é específico e indispensável ao desenvolvimento dessa atividade.

Nos depoimentos dos professores, observam-se indicativos de que existe uma preocupação com a formação profissional. Note-se um exemplo de como os participantes expõem essa questão:

[...] mas eu estou trabalhando leitura e já estou falando, vocês vão ser professores, como é que vocês vão fazer para o seu aluninho ler. Como é que vocês vão fazer para ele escrever? Ou vai mandar escrever e vai ficar por isso mesmo, não vai ensinar nada. Então eu procuro desde o primeiro dia que eu dei aula aqui passar essa responsabilidade, 
dividir isso com eles e ensinar pra eles o que eu sei. (Maitê, Letras, Instituição B).

Dessa vez eu pedi um resumo, porque resumo é ótimo, você percebe se eles sabem fazer, se eles sabem ler; aí veio todo tipo de coisa, fichamento, paráfrases longas e toda uma série de coisa. Aí eu levei o material para discutir com eles e aí comecei meio dura: porque se vocês vão dar aula de português, vocês têm de saber português... o fulano vai dar aula de acentuação e me escreve um relatório sem nenhuma crase no lugar certo, por exemplo. Crase é assim, parece que desapareceu ou vale tudo, os de matemática não estão preocupados com isso, mas os de português são de uma linguagem muito banal, muito pouco técnica, são de pouca leitura. (Paula, Letras, Instituição C).

Por estarmos num curso de licenciatura, os professores precisam ter uma postura tal em sala de aula que promova nos alunos uma outra postura como professores. Então nós não podemos ser professores de giz e lousa, temos que ter uma proposta diferente em sala de aula [...] de nós sermos um pouco mais de modelo para eles, nas nossas aulas, quer dizer, se nós não tivermos uma postura diferente em nossas aulas, os nossos alunos não vão ter. (Sueli, Instituição D).

Observa-se pelos depoimentos que a formação para a docência é um importante elemento orientador da prática e que é preciso, durante as aulas e na relação com os alunos, enfatizar que o objetivo do curso é a formação do professor. Alguns formadores destacam, inclusive, que é necessário oportunizar espaços para que o futuro professor vivencie a docência. Ficou evidente que os formadores compreendem como necessária a relação entre teoria e prática nos relatos sobre como procuram promover essa articulação.

Como nas entrevistas é recorrente essa preocupação em estabelecer a relação entre teoria e prática, em preparar os alunos para a formação profissional, considerou-se necessário consultar os projetos de formação dos cursos em que esses professores atuam para verificar como essa questão está contemplada. Nas propostas dos cursos, a integração entre a dimensão teórica e a dimensão prática está prevista especialmente nas disciplinas de metodologia e didática, bem como no estágio curricular supervisionado. Nos documentos analisados, observa-se a presença de um discurso a favor da articulação entre teoria e prática; no entanto, as práticas formativas que serão mobilizadas para promover essa articulação são pouco explicitadas. As entrevistas confirmam que a tarefa de articular teoria e prática ocorre mais no interior de cada disciplina, por meio de exemplos ou situações contextualizadas, do que em um projeto envolvendo vários componentes curriculares.

Se, por um lado, os professores formadores fazem todo esforço para repensar seus saberes e suas práticas frente às exigências impostas pelas novas condições docentes, por outro, esbarram em vários tipos de resistências que dificultam os avanços e favorecem os conflitos. Observou-se que essas resistências têm origem nas propostas de formação, na política institucional e na cultura docente.

Tanto a política institucional como as propostas de formação analisadas mantêm uma rígida organização dos tempos e dos espaços de 
aprendizagem. Não há, por exemplo, uma política e formas de gestão que favoreçam o trabalho coletivo. A organização curricular dos cursos de formação é pouco flexível, as mudanças estabelecidas pelas políticas de formação não alteraram significativamente o projeto de formação desenvolvido pelos cursos nem incorporaram as novas demandas, como o "novo aluno" e a escola básica em crise.

\section{À guisa de conclusão}

Nas instituições investigadas, as iniciativas para obter melhores resultados nas práticas formativas ocorrem principalmente no âmbito individual ou, quando muito, em parcerias compostas por dois ou três professores que têm maior empatia. Faltam ações de âmbito institucional, projetos pedagógicos que não sejam mera formalidade.

Os entrevistados relatam as dificuldades de trabalhar conjuntamente, associar interesses e promover a articulação entre as disciplinas, como explica uma professora:

Um desafio? Uma discussão entre os professores de didática para oxigenar. Cada um dá seu curso sozinho. Não tem tempo. A gente corre muito. Aqui não há essa troca. Por que é um desafio? Porque o curso continua. Você fala do projeto pedagógico para os alunos e aqui a gente não tem. Eu tenho vergonha de falar para eles. Seria bem legal se isso acontecesse. (Cristina, História, Instituição C).

Alguns professores chegam a dizer que há uma cultura instalada que os impulsiona a trabalhar isoladamente:

Então, essa questão do trabalho solitário, individual é... que acaba criando uma cultura, também. Quer dizer, acaba criando não, porque é essa cultura que está instalada. Desse trabalho solitário, individual, onde ninguém sabe quem está pesquisando o que, o que cada um está fazendo. (Nair, Geografia, Instituição C).

Para autores como Sarmento (1994) e Morgado (2005), o isolamento profissional no magistério é um aspecto da cultura docente que tem sido favorecido tanto pela organização dos tempos e dos espaços como pela organização curricular nas instituições de ensino.

E no caso do ensino superior, como bem explica Roldão (2005, p. 122), a cultura do individualismo também se configura pela cátedra, ou seja, o docente universitário historicamente é considerado detentor de um saber privilegiado em que a docência como prática individual se preserva e é tida como símbolo de poder. Segundo a autora, mesmo o ensino superior tendo sido desafiado na modernidade a investir na produção experimental e investigativa que requereu a ruptura com o trabalho individual em favor das equipes de pesquisa, "[...] o peso do poder individual, no que se refere à docência, não foi ainda, em termos de cultura profissional, contaminado por este desejável trabalho interpares que a investigação exige". 
Roldão (2005, p. 122) chama a atenção para a importância de se reconhecer "[...] a força da cultura instalada, no plano social e simbólico", para que seja possível introduzir mudanças graduais que possibilitem tornar a ação de ensinar uma forma mais elaborada de promover a apropriação do conhecimento pelo estudante.

Os próprios formadores reconhecem que o isolamento do trabalho docente constitui um obstáculo não só ao acesso e à partilha de novas ideias, como à possibilidade de encontrar soluções para os problemas e desafios enfrentados (Morgado, 2005). É certo que a solidão do trabalho docente refreia as possibilidades de as instituições apresentarem proposições mais avançadas e consistentes para formar professores.

Analisando as políticas de formação de professores, Arroyo (2007) observa que a crise de legitimidade da instituição escolar, relacionada à perda dos ideais civilizatórios que sustentaram o desenvolvimento e a expansão da educação básica, é também uma crise dos modelos de formação dos professores. Segundo o autor, é preciso construir novos parâmetros de formação, tomando como referência a condição docente em seu acontecer histórico, num diálogo permeado pela dinâmica das transformações sociais, políticas e culturais.

Os dados do presente estudo desvelam, com muita nitidez, múltiplos ângulos da condição docente num mundo em mudança e desenham os contornos de uma crise, que requer a urgente reconfiguração dos modelos formativos.

Confrontados com a necessidade de preparar para a docência os jovens que chegam hoje à universidade, com um perfil muito diferente do esperado, os formadores se encontram diante do dilema de formar esse "aluno possível" para uma "docência possível", nas situações concretas do trabalho nas escolas.

Embora tenham sido identificadas várias iniciativas por parte dos professores formadores, para mudar suas práticas docentes em resposta aos novos desafios do seu trabalho no ensino superior, concluiu-se que o contexto institucional em que atuam constitui mais um obstáculo do que um fomento à transformação das práticas formativas.

\section{Referências bibliográficas}

ANDRÉ, M. E. D. A. Estudo de caso em pesquisa e em avaliação educacional. Brasília: Liberlivro, 2005.

APPLE, M. Trabalho docente e textos: economia política das relações de classe e gênero em educação. Porto Alegre: Artes Médicas, 1995.

ARROYO, M. G. Condição docente, trabalho e formação. In: SOUZA, J. V. A. (Org.). Formação de professores para a educação básica.

Belo Horizonte: Autêntica, 2007. p. 191-210. 
BORGES, C.; TARDIF, M. Apresentação. Educação e Sociedade, Campinas, SP: v. 74, n. 22, p.11-26, 2001.

BRASIL. Lei no 9.394, de 20 de dezembro de 1996. Estabelece as diretrizes e bases da educação nacional. Diário Oficial da União, Brasília, 23 dez. 1996. Disponível em: <www.planalto.gov.br/CCIVIL/ LEIS/19394.htm>.

BRASIL. Conselho Nacional de Educação. Conselho Pleno. Resolução $\mathrm{CNE} / \mathrm{CP} \mathrm{n}^{\circ}$ 1, de 18 de fevereiro de 2002. Institui Diretrizes Curriculares Nacionais para a Formação de Professores da Educação Básica, em nível superior, curso de licenciatura, de graduação plena. Diário Oficial da União, Brasília, 9 abr. 2002, Seção 1, p. 31. Republicada por ter saído com incorreção do original em 4 mar. 2002, Seção 1, p. 8. Alterada pela Resolução CNE/CP n 2, de 27 ago. 2004, que adia o prazo previsto no art. 15. Alterada pela Resolução CNE/CP no 1, de 17 nov. 2005, que acrescenta um parágrafo ao art. 15. Disponível em: <http://portal.mec.gov.br/cne/arquivos/pdf/rcp01_02.pdf>.

CUNHA, M. I. Ensino como mediação da formação do professor universitário. In: MOROSINI, M. C. Professor do ensino superior: identidade, docência e formação. Brasília: Inep, 2000. p. 53-60.

Globalização, educação e formação docente. Educação e Linguagem, São Paulo, n. 9, p. 145-158, jan./jun. 2004.

GATTI, B. A. A formação dos docentes: o confronto necessário professor x academia. Cadernos de Pesquisa, São Paulo, n.81, p. 70-74, 1991.

GATTI, B. A.; BARRETTO, E. S. de S. Professores do Brasil: impasses e desafios. Brasília: Unesco, 2009.

IMBERNÓN, F. Formação docente e profissional: formar-se para a mudança e a incerteza. São Paulo: Cortez, 2002.

LESSARD, C.; TARDIF. M. As transformações atuais do ensino: três cenários possíveis na evolução da profissão de professor? In: LESSARD, C.; TARDIF. M. (Orgs.). O ofício de professor: histórias, perspectivas e desafios internacionais. Petrópolis, RJ: Vozes, 2008. p. 255-277.

MARIN, A J.; GIOVANNI, L. M. Expressão escrita de concluintes de curso universitário para formar professores. Cadernos de Pesquisa, São Paulo, n. 37, p. 15-41, 2007.

MARIN, A. J.; GIOVANNI, L. M. A precariedade da formação de professores para os anos iniciais da escolarização: 35 anos depois 
do início da formalização de novos modelos. In: LAZZARI, Raquel L. B.

MARX, K.; ENGELS, F. A ideologia alemã: teses sobre Feuerbach. Trad. Silvio Donizete Chagas. São Paulo: Centauro, 2002.

MORGADO, J. C. Currículo e profissionalidade docente. Porto, Portugal: Porto Ed., 2005.

MIZUKAMI, M. G. N. Aprendizagem da docência: professores formadores. In: ROMANOWSKI, J.; MARTINS, P. L.; JUNQUEIRA, S. R. A. (Orgs.). Conhecimento local e conhecimento universal: formação docente, aprendizado e ensino. Curitiba, PR: Universitária Champagnat, 2005. v. 5, p. 69-80.

NISBET, J.; WATT, J. Case study. Nottingham, UK: University of Nottingham, School of Education, 1978. (Readguide 26: Guides on Education Research).

NÓvOA, A. Vida de professores. Porto, Portugal: Porto Ed., 2000.

ROLDÃO, M. do Céu. Profissionalidade docente em análise:

especificidades dos ensinos superior e não superior. Nuances: Estudos sobre Educação, Presidente Prudente, v. 11, n. 13, p. 105-126, 2005.

SARMENTO, M. J. A vez e a voz dos professores: contributo para o estudo da cultura organizacional da escola primária. Porto, Portugal: Porto Ed., 1994.

SHULMAN, L. S. The wisdom of practice: essays on teaching and learning to teach. San Francisco: Jossey-Bass, 2004.

STAKE, R. E. The art of case study research. Thousand Oaks, CA: Sage, 1995.

TARDIF, M.; LESSARD, C. O trabalho docente: elementos para uma teoria da docência como profissão de interações humanas. Petrópolis, RJ: Vozes, 2005.

VÁSQUEZ, A. S. Filosofia da práxis. Buenos Aires: Consejo Latinoamericano de Ciências Sociais (Clacso); São Paulo: Expressão Popular, 2007. 
Marli Eliza Dalmazo Afonso de André, doutora em Psicologia da Educação pela University of Illinois, USA, é professora do Curso de Pós-Graduação em Educação: Psicologia da Educação, da Pontifícia Universidade Católica de São Paulo (PUC-SP).

marliandre@pucsp.br

Patrícia C. Albieri de Almeida, doutora em Educação pela Universidade Estadual de Campinas (Unicamp) e pós-doutora em Psicologia da Educação pela Pontifícia Universidade Católica de São Paulo (PUC-SP), é professora do Centro de Ciências e Humanidades da Universidade Presbiteriana Mackenzie.

patricia.aa@uol.com.br

Marcia de Souza Hobold, doutora em Psicologia da Educação pela Pontifícia Universidade Católica de São Paulo (PUC-SP), é professora do Departamento de Psicologia da Universidade da Região de Joinville (Univille).

gmhobold@terra.com.br

Neusa Banhara Ambrosetti, pós-doutora em Psicologia da Educação pela Pontifícia Universidade Católica de São Paulo (PUC-SP), é professora e coordenadora de cursos de graduação e pós-graduação na Universidade de Taubaté e pesquisadora na área de formação de professores.

nbambrosetti@uol.com.br

Laurizete Ferragut Passos, doutora em Educação pela Universidade de São Paulo (USP), é professora do Programa de Estudos Pós-Graduados em Educação Matemática da Pontifícia Universidade Católica de São Paulo (PUC-SP).

laurizet@terra.com.br

Ana Lúcia Manrique, doutora em Psicologia da Educação pela Pontifícia Universidade Católica de São Paulo (PUC-SP), é professora do Departamento de Matemática e do Programa de Estudos Pós-Graduados em Educação Matemática dessa universidade.

manrique@pucsp.br

Recebido em 15 de março de 2009.

Aprovado em 15 de dezembro de 2009. 